\title{
Discussion on The Construction of The Quality Management System of PE Teaching in Colleges and Universities
}

\author{
Yan $\mathrm{Xu}^{1}$ \\ ${ }^{1}$ Chengdu Medical College, Chengdu, Sichuan province, China
}

\begin{abstract}
Keywords: PE Teaching in Colleges and Universities; Teaching Quality; Construction of Management System.
\end{abstract}

\begin{abstract}
PE teaching is an important part of Chinese higher education. However, the reform and development of PE teaching in China has not kept pace with the development of education at present. Especially the imperfection of the teaching quality management system and the mechanism have seriously affected the quality of PE teaching. This paper expounds the necessity and feasibility of constructing teaching quality management system in colleges and universities of the country. It also analyzes the five elements of the quality management system of PE teaching in colleges and universities and puts forward an idea that the management system of PE teaching can be constructed by building the measurement system, feedback system and other systems of PE teaching.
\end{abstract}

\section{Introduction}

With the rapid development of China's economy and the continuous improvement of people's living standard, daily life is getting more and more comfortable. It caused the decline of students' physical fitness level which has caught the education department's attention. The quality of PE teaching is a part of the quality of higher education. It is key to improve PE teaching quality by constructing the quality management system of PE teaching. Therefore, the construction of quality management system of PE teaching in colleges and universities is an important guarantee to enhance the quality of PE teaching.

The Necessity and Feasibility of Implementing The Quality Management of PE Teaching in Colleges and Universities

The Necessity of Implementing The Quality Management of PE Teaching in Colleges and Universities. The implementation of the quality management of PE teaching embodies people-oriented outlook of scientific development. Its main purpose is to realize people's all-round development. Colleges and universities are the main positions for students to develop their thoughts, knowledge and both mental and physical quality. The implementation of PE teaching quality management is a realistic requirement to improve the level of higher education. Nowadays, China should foster the talents who adapts to market changes according to the development of the society. Thus, it is necessary to intensify education innovation, deepen the education reform and improve the quality of education. In terms of PE teaching, the construction of quality management system can effectively improve the teaching quality, which is the inevitable requirement of the reform and development of PE teaching.

The Feasibility of implementing the Quality Management of PE Teaching in Colleges and Universities. Quality management mode is a kind of mode that satisfies customers' demand by using limited resources. It is not only applicable to industrial and commercial management, also suitable for management of nonprofit organizations such as education, health care department. The management principles of the quality of $\mathrm{PE}$ teaching require full participation and continuous improvement. It requires employees to do their best to complete their duty well, clear their responsibilities, be fully aware of their teaching tasks and goals, play a role adequately in personal wisdom in order to promote the teaching quality. Continuous improvement requires to establish suitable quality management 
mode of PE teaching and improve personnel, information resources, management objectives and quality level continuously [1]. With the continuous development of the society and the demand of innovative talents, colleges and universities need to improve the content, modes and teaching management to fit in the requirement of education reform and development and cultivate high quality talents.

\section{The Elements of Quality Management System of PE Teaching in Colleges and Universities}

Management Responsibility. Management responsibility is the key to construct quality management system of PE teaching in colleges and universities. The work of PE administrators mainly focus on two aspects: policies and objectives of system quality management. PE departments in schools undertake sport activities of all the teachers and students. It needs to provide technical guidance and hardware services to teachers and students. It is required to ensure the quality of service and take effective measures to improve the service efficiency as well. It should be noted that the goal is to be implemented gradually according to the actual situation of schools.

Resource Management. The resource management of PE teaching quality in colleges and universities mainly consists of three parts: human resource, information resource and materials resource. In human resource management, the human factor is the most important. The staff should be both restrained and be fair in meting out rewards and punishments. Information resource management is the foundation of PE teaching in colleges and universities. It is mainly carried out by the requirements given by superiors. Students can also get information resource through web sites, publicity and other means. Resource management mainly consists of educating students, providing facilities and areas etc.

Service Implementation Process. Service implementation process includes the process of design, development and service of PE curriculum resources. In this process, analyzing the students' demand comes in the first place. Secondly, a feasible schemes should be made according to the actual situation of the colleges. The implementation of the service process is affected by these three processes, and is also influenced by the feedback of service quality monitoring. In the process of the course development, the demand of students needs to be investigated in order to form the service requirements.[2]

Measurement Analysis and Improvement. The operation of the quality management system of $\mathrm{PE}$ teaching in colleges and universities needs to be self-improved. The process of recognizing the implementation of the service in time needs to take effective means to solve the problem through measurement and analysis techniques. This mechanism not only enhances the students' enthusiasm towards sports, but also greatly improves the quality of PE teaching.

\section{The Main Problems of The Quality Management System of PE Teaching in Chinese Colleges and Universities}

The Concept of Teaching Quality Management Lags, Which Affects The Improvement of The Quality Management Level. The quality management concept of PE teaching in Chinese colleges and universities is backward, which leads to the lack of supervision mechanism of management system. Education quality management concept must keep pace with the times. Only by constantly updating management concept can promote the education quality management level fundamentally. However, the quality management of PE teaching in colleges and universities nowadays falls behind, the management system is not rigorous and the operability is not high enough. These disadvantages result in the dissatisfaction of student's actual demand, which has restricted the development of teaching quality.

The Thought of PE Teaching Is Not Clear, Which Leads to Unreasonable Orientation. It mainly manifests two aspects for PE teaching in colleges and universities to pursue the enhancement unilaterally of students' short-term athletic quality: On one hand, the course limits students' requirements of learning all aspects of knowledge. On the other hand, the teaching content is not in conformity with students' demand. Both of the two aspects affect the students' correct cognition of PE 
teaching. It makes students be less enthusiastic about sports and even think that sport is not important, which can lead to boredom of study.

The Lack of Quality Monitoring Methods. The Evaluation System Is Not Scientific. Nowadays, the lack of quality monitoring methods of PE teaching in colleges and universities embodies in two aspects. Firstly, teachers teach in class according to the teaching goals and teaching content but they are not responsible for supervising and managing students' mastery degree to which the students are taught. Meanwhile, teachers lack the information collection and feedback of students' mastery degree. In this case, the teaching quality is affected directly. [3] Secondly, in the teaching process teachers are partial to the student's sports target rate. In this way, the disqualification of students' sports standard is seen as a failure of the enterprise product. Therefore, teachers need to recognize correctly the problem of students' target rate.

PE Teachers Have The Problem of " Appreciating Scientific Research, Despising Teaching ". The Teaching Energy Is Inadequately Invested. Nowadays, teachers in colleges and universities are influenced deeply by external factors, such as title assessment. Therefore, the problem of " appreciating scientific research, despising teaching " exists widely. There are many reasons to explain this phenomenon . The main reason is the lack of corresponding management system of teaching quality. Under the influence of this reason, teachers in colleges and universities devote inadequately to teaching. Moreover, they are easy to be satisfied with the status quo and their teaching ideas are not easy to be changed.

\section{Measures of Constructing The Quality Management System of PE Teaching in Colleges and Universities}

Establish The Quality Evaluation System of PE Teaching. The comprehensive evaluation of the quality of PE teaching is an important guarantee to improve the quality of PE teaching in colleges and universities. It is also an important part of the quality management system. The teaching quality evaluation is also one of the most commonly used methods for education management department to manage efficiently. Training talents is the education goal of colleges and universities all the time. Thus improving the teaching quality is the top priority. Through establishing the quality evaluation system of PE teaching quality, teachers can feedback quality information of teaching and improve teaching methods continually through various channels so as to improve both the teaching level and quality. PE teaching evaluation is the periodic quality evaluation. It is a quality evaluation system of $\mathrm{PE}$ teaching with real Chinese characteristics, which should make all the teachers and students understand the importance of PE teaching and the quality evaluation of PE. The school shall publish the evaluation results regularly and subject to the supervision and inspection of all walks of life. The evaluation of PE teaching need full participation, formulate relevant evaluation system, mobilize the enthusiasm of teachers and stimulate students' learning enthusiasm. In this way, the quality of PE teaching can be improved steadily.

Establish Sensitive Feedback System of Quality Management. Information is the key of the quality management of PE teaching in colleges and universities. In order to ensure the normal operation of the quality management system, the established feedback system of quality management should make instant feedback to internal and external information effectively. By Implementing the comprehensive evaluation of teaching quality, the needs of students and the teaching quality of teachers can be grasped timely, conveniently and effectively. It is also convenient to make timely adjustments toward the teaching content, teaching methods and teaching objectives. A sensitive feedback system of PE teaching quality management is able to be established by organizing a team consists of teaching messengers and teaching supervisors. Collecting information through online teaching quality evaluation, questionnaire survey, the student forums, online email and periodic random access and etc. Then analyzing and giving feedback the problems in teaching, management and some other aspects so that problems can be resolved in time. Schools should establish an effective feedback system by making full use of human resource management system. The feedback information should be published in brief reports regularly. The information collected from teachers, students and experts should be analyzed and summarized. Also, it is important to make teachers and 
students value the process and results of the information gathering, and improve the efficiency and quality of the feedback information.[4]

Establish The Realistic Target System of Quality Management. In order to guarantee the effective improvement of teaching quality, colleges and universities should make a viable target system, make the functions of quality management system independent, monitor and evaluate its course quality efficiently and develop a reasonable quality management objectives. It is well known that PE teaching is of great particularity. Each school is different in the developing levels. Nowadays, the development of PE teaching in Chinese colleges and universities is relatively slow. There is still a large gap compared with other professional courses. So, we should make specific analysis on the specific situation of each school. We should also improve teaching content, teaching mode and other parts according to the specific needs of school students and develop a practical teaching goal. The goal should cover the whole content of PE teaching outline, formulate specific standards for each item. It is also necessary to analyze and study quantitatively and qualitatively the reliability of making standards and the feasibility of setting goals.

Establish A Strict Responsibility System of Quality Management. The construction of the quality management system of PE teaching in colleges and universities requires a thorough analysis of each teaching related system and clarifies the management responsibility of teaching quality. In addition, in order to better implement the quality objectives, principles and the work of each quality management system, the responsibilities of each department personnel should be clarified by colleges and universities so that personnel can coordinate with each other and the teaching work can be carried out orderly. It is necessary to establish the quality management responsibility system, which can make clear rules for the quality of teaching, the responsibilities of employees and the system of rewards and punishments. If necessary, the rules can be printed manuals and distributed to everyone. It helps everyone understand their respective responsibilities, take the initiative to assume their responsibilities, and perform each responsibility within the scope of the reasonable control of the quality management system. the teaching management system to achieve it plays an important role in the good effects achieved by teaching management system. [5]

Establish Command System of Teaching Decision. The management of PE teaching is a combined system of multi-elements, multiple functions and complex structure. the quality management system is made up of command system of PE teaching decision, the evaluation system of teaching quality, the feedback system of quality management, responsibility system of quality management and other components of the system. They have different functions and they coordinate ad cooperate with each other. The system of teaching decision is the center of the teaching command system, which is the center of the whole system of teaching quality management. The management of PE teaching should not only serve teaching, but also guide and manage teaching. Only by building highly efficient command system of teaching decision can realize the scientific, democratic and modern management in a real sense so that the management system of the quality can be ensured operating normally. [6] Under the unified leadership of the principles, the implementation of the teaching work mainly adopts the three level teaching management mode(school, college, department), which is mainly supervised by the deputy principal. The highest level of teaching management system is composed of party and government leadership. In order to make the PE teaching work smoothly, a steering committee is also needed, which consists of five subordinate committees (the management and analysis of teaching quality committee, teaching equipment committee, students' quality committee, the construction and management of teaching material committee, the construction of teaching staff committee). All of them are jointly responsible for commanding, arguing, consulting and supervising the decision of PE teaching management. The highest decision-making layer of teaching management devolves power, which expands the autonomy of the secondary departments' teaching management, the right to use the funds and the right to employ teachers. The major decisions of PE teaching are put forward as schemes by the office of academic affairs according to the investigation and analysis of the evaluation system of the quality management and the information of the feedback system. Then the commission and the highest decision-making layer will make the final decision. Moreover, it is necessary to hold a regular meeting on the quality of 
PE teaching to study the problems and solutions in the process of PE teaching.[7] The command of $\mathrm{PE}$ teaching decision is a combination of leadership and hierarchical management, a combination of process and objective management. The implementation of these measures above can guarantee the quality of PE teaching.

As an important part of education content in colleges and universities, the concept of PE teaching should be updated in the teaching process, the management idea should be clarified, the management system should be perfected, the management system of quality should be constructed efficiently and the teaching quality should be surely guaranteed. All in all, with the continuous deepening of education reform, colleges and universities should attach importance to the quality of PE teaching. Constructing the management system of teaching quality is an important measure to ensure the improvement of teaching quality. It is also an important guarantee for the healthy development of PE courses.

\section{References}

[1] Yifei Shan, The Thoughts about The Construction of The Quality Management System of PE Teaching in Colleges And Universities[J], Journal of Xinxiang college, 2015(5).

[2] Songwei Wu, The Construction of The Quality Security System of PE Teaching in Universities [J], Modern commercial industry, 2016(28).

[3] Jitao Pu, The Construction of PE Teaching Environment in Ordinary Colleges And Universities[J], PE Science, 2016(1).

[4] Jinsong Zhang, Shuwei Zhang, The Research on The Construction of The Quality Assurance System of PE Teaching in Colleges and Universities[J], Journal of Liaoning technology university (social science), 2010, 12(3).

[5] Chun Chen, Dong Zhong, The Construction of The Management And Monitoring System of The Comprehensive Teaching Quality in Sports Colleges [J], Journal of Hubei institute of science and technology, 2015(11).

[6] Qing Wang, Yong Xiang, The Construction of Monitoring System of PE Teaching Quality in Colleges And Universities Based On The TQC Theory [J], Managerialist,2013 (1).

[7] Xiuying Yang, The Thinking And Countermeasure of Constructing The Quality Assurance System of PE Teaching in Colleges And Universities[J], Contemporary Sports Technology, 2015, 5(19). 